\title{
Improved molecular diagnosis of facioscapulohumeral muscular dystrophy(FSHD): validation of the differential double digestion for FSHD
}

\author{
M Upadhyaya, J Maynard, M T Rogers, P W Lunt, P Jardine, D Ravine, P S Harper
}

\begin{abstract}
A major advance in the molecular diagnosis of facioscapulohumeral muscular dystrophy is the recently reported elimination of confounding DNA fragments arising from homologous sequences located at $10 \mathrm{q} 26$. In order to evaluate the specificity and sensitivity of this important diagnostic test, we have compared a group of 130 patients fulfilling the diagnostic criteria for FSHD with 200 control subjects not known to have an increased risk of having an FSHD mutation. Among the FSHD cases the smallest $B \ln I / E c o R I$ fragment sizes ranged from 10 to $>48 \mathrm{~kb}$ with $\mathbf{9 4 . 6 \%}$ (95\% CI $89.2-97.8 \%)$ of cases having fragment sizes of $34 \mathrm{~kb}$ or less. Among the 400 chromosomes from controls the smallest $B \ln I / E c o R I$ fragment observed with the $E c o R I / B \operatorname{lnI}$ double restriction enzyme digest was $38 \mathbf{k b} \pm 2 \mathbf{k b}$, suggesting a test specificity at a fragment size $<34 \mathrm{~kb}$ of or very near to $100 \%$ (lower $95 \%$ CI $98.2 \%)$. Test sensitivity at $<34 \mathbf{k b}$ is estimated at $94.6 \%$ (95\% CI 89.2-97.8\%), all outliers having fragments $>38 \mathrm{~kb}$. The Southern blot analysis with DNA probe p13E-11 has created a valuable molecular diagnostic test for FSHD. (f Med Genet 1997;34:476-479)
\end{abstract}

Keywords: molecular diagnosis; FSHD; sensitivity

Institute of Medical Genetics, University of Wales College of Medicine, Heath Park, Cardiff CF4 4XN, UK M Upadhyaya J Maynard

M T Rogers

D Ravine

P S Harper

Bristol Royal Hospital for Sick Children, St

Michael's Hill, Bristol BS2 8BJ, UK

P W Lunt

P Jardine

Correspondence to: Dr Upadhyaya.

Received 27 August 1996 Revised version accepted for publication 20 January 1997 disease locus may be unlinked to $4 \mathrm{q} 35,{ }^{6}$ but no other specific chromosomal locations have yet been identified. To date, the molecular prediction of FSHD with D4F104S1 has been most mapped to $4 \mathrm{q}^{3} 5^{3}$ and is closely linked to the locus D4F104S1 defined by the probe p13E-1 $1 .{ }^{45}$ In a small minority of FSHD families (estimated to be $5-10 \%$ at most), the

Facioscapulohumeral muscular dystrophy cular disorder characterised by progressive face, upper arm, and shoulder girdle. The within and between families. Disease onset patients eventually becoming wheelch bound and with up to two-thirds of patients having disease related problems in their daily (anger and gradually progresses with about $20 \%$ of secure in those families which are linked to other $4 \mathrm{q} 35$ markers but has not permitted a molecular diagnostic test for general application. ${ }^{7}$ Even in some $4 \mathrm{q} 35$ linked families with small D4F104S1 EcoRI fragments, testing has been complicated by recombinations occurring between the locus D4F104S1 and FSHD, with a maximum reported recombination fraction of $0.05 .^{8}$

Using the restriction enzyme $E c o$ RI, the probe p13E-11 identifies two highly polymorphic loci located at $4 \mathrm{q} 35$ and $10 \mathrm{q} 26$. The polymorphic EcoRI fragment at $4 \mathrm{q}$ is composed almost entirely of $3.3 \mathrm{~kb} \mathrm{KpnI} \mathrm{tandem} \mathrm{repeat}$ units identified as D4Z4. ${ }^{9}$ Among chromosomes from control subjects, the size of the $4 \mathrm{q}$ derived fragments usually ranges from $40 \mathrm{~kb}$ to approximately $200 \mathrm{~kb},{ }^{10}$ whereas in two-thirds of FSHD patients, a deletion of an integral number of the $\mathrm{D} 4 \mathrm{Z} 4$ repeats generates a shortened $E c o$ RI fragment which is usually smaller than $28 \mathrm{~kb}^{4}{ }^{5}$ Unfortunately, the size distribution of approximately $10 \%$ of $E c o R I$ fragments from the homologous polymorphic locus at $10 \mathrm{q}$ overlaps with the range seen in FSHD cases, ${ }^{10}$ and consequently many non-FSHD cases have $E c o$ RI fragment sizes of less than 28 $\mathrm{kb}$, thus giving a test specificity from $E c o \mathrm{RI}$ digest alone of $76 \%$ at this level. ${ }^{4}{ }^{5} \mathrm{It}$ is evident that these smaller polymorphic EcoRI fragments arising from the $10 \mathrm{q}$ locus, coupled with the lesser risks of recombination and locus heterogeneity, create considerable difficulties when assessing the diagnostic significance of a shortened fragment in a person with clinical features suggestive of FSHD or in an at risk relative from a family with FSHD.

Recent detection of sequence divergence between the KpnI tandem repeat units located at $4 \mathrm{q}$ and $10 \mathrm{q}$ has shown a different distribution of restriction enzyme sites, and has shown that the enzyme $B h I$ I specifically cleaves the 3.3 $\mathrm{kb}$ repeats derived from $10 \mathrm{q}$, leaving intact the tandem repeat units at $4 \mathrm{q}^{.11}$ Thus, a double restriction enzyme digest (DD) with the enzymes $E c o$ RI and $B h I$ allows the specific detection of $4 \mathrm{q}$ fragments and should greatly facilitate the molecular diagnosis of FSHD. In order to define the sensitivity and specificity of this improved molecular test, we have rescreened samples from a group of previously diagnosed FSHD patients, as well as from a group of unaffected controls. 

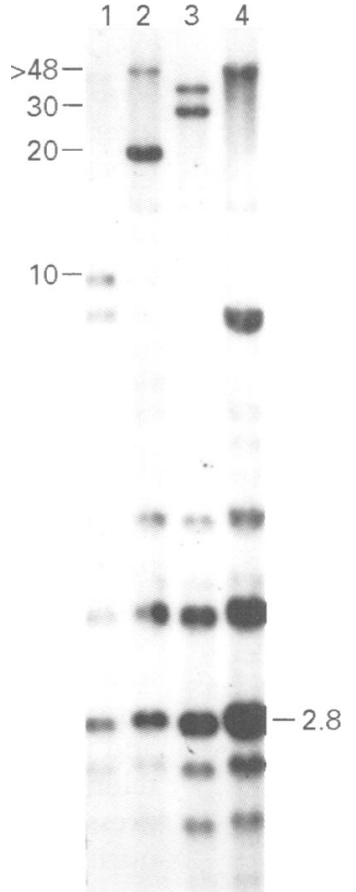

Figure 1 The distribution of the smallest EcoRI/BlnI fragment sizes. Lane 4 contains DNA sample from a control subject. Lanes 1-3 contain samples from FSHD patients with smallest EcoRI/BlnI fragment sizes of 10, 20 and $30 \mathrm{~kb}$ respectively. The $9.4 \mathrm{~kb}$ band specific to the $Y$ chromosome is observed in lanes 1 , and 4 . The presence of the $2.8 \mathrm{~kb}$ fragment is generated as a result of complete digestion of the $10 \mathrm{q}$ fragment with the enzyme BlnI.

\section{Subjects and methods}

Affected cases were selected at random from familial and sporadic cases of FSHD studied over the past 10 years. The clinical record of each patient was reviewed and only those with an unequivocal diagnosis of FSHD or scapulohumeral dystrophy were included. ${ }^{12}{ }^{12}$ One hundred and thirty unrelated FSHD patients were studied, of whom 27 represented new mutation cases with apparently normal parents. The control group comprised 200 subjects with no known background family history of FSHD. Blood was collected from all patients and controls and high molecular weight DNA isolated by use of standard methods. Using the same method previously used for the restriction enzyme $E c o$ RI, $10 \mu \mathrm{g}$ genomic DNA was simultaneously digested with $E c o$ RI and $B \ln \mathrm{I}$ (Amersham) for eight hours and then fractionated on a $0.5 \%$ agarose gel for 48 hours at 0.5 volts $/ \mathrm{cm}$. High molecular weight DNA markers (Gibco BRL) were used for accurate sizing of the double digested fragments (fig 1). The DNA on the gel was irradiated with $260 \mathrm{~nm}$ UV light for 60 seconds to induce random "nicks" throughout the DNA which was then transferred onto a Zetaprobe membrane (Bio$\mathrm{rad}$ ) by Southern blotting. The $800 \mathrm{bp}$ insert from p13E-11 was labelled with $\left[{ }^{32} \mathrm{P}\right] \mathrm{dCTP}$ using primer extension. ${ }^{13}$ The posthybridisation wash was $2 \times \mathrm{SSC}, 0.1 \%$ SDS at $65^{\circ} \mathrm{C}$ as required, followed by autoradiography for one to seven days at $-70^{\circ} \mathrm{C}$ using Fuji $x$ ray film with an intensifying screen. To determine the accuracy of our assessment of fragment sizes, repeated measurements of the fragments of 30 affected subjects with shortened fragments and 105 controls with fragment sizes between 38
Table 1 Details of subjects and families clinically affected with FSHD with an EcoRI/BInI smallest fragment greater than $35 \mathrm{~kb}$

\begin{tabular}{lll}
\hline $\begin{array}{l}\text { FSHD } \\
\text { family No }\end{array}$ & $\begin{array}{l}\text { Smallest } \\
\text { fragment } \\
\text { size }(\mathrm{kb})\end{array}$ & Clinical details \\
\hline 221 & 38 & $\begin{array}{l}\text { Typical small FSHD family } \\
\text { Assumed sporadic case, onset in } \\
\text { infancy } \\
\text { Typical FSHD, 2 affected members in } \\
\text { 2 generations. Linkage of disease to } \\
\text { 4q35 unclear although 38 kb fragment } \\
\text { appears 4q35 linked }\end{array}$ \\
224 & 38 & $\begin{array}{l}\text { Brother and sister with typical but } \\
\text { mild FSHD } \\
\text { "FSHD plus". Classic FSHD plus } \\
\text { hypothyroidism or early cardiac death, } \\
\text { separately, in daughters of historically } \\
\text { affected mother } \\
\text { Sporadic FSHD with de novo 48 kb } \\
\text { fragment }\end{array}$ \\
016 & 42 & $\begin{array}{l}\text { Four affected sibs with typical FSHD, } \\
\text { father very mild. Distant } \\
\text { consanguinity (parents second cousins } \\
\text { once removed) }\end{array}$ \\
\hline 334 & 74 &
\end{tabular}

and $48 \mathrm{~kb}$ showed a variation of reported fragment size that was $\pm 1 \mathrm{~kb}$ for fragments up to 30 $\mathrm{kb}, \pm 2$ for those from 30 to $40 \mathrm{~kb}$, and \pm 3 for those greater than $40 \mathrm{~kb}$. The autoradiographs were assessed blindly by two separate observers. A $95 \%$ CI (confidence interval) was calculated using the Clopper-Pearson exact method. ${ }^{14}$

\section{Results}

Among those with previously diagnosed sporadic or familial FSHD, the size of the smaller fragment varied from $10 \mathrm{~kb}$ to $>48 \mathrm{~kb}$ (fig 2). One hundred and twenty-three out of the 130 FSHD patients (94.6\%) (95\% CI 89.2-97.8\%) had fragment sizes that were $34 \mathrm{~kb}$ or less. Among the seven cases with larger fragments, the fragment sizes varied from $38 \mathrm{~kb}( \pm 2 \mathrm{~kb})$ to $>48 \mathrm{~kb}$. The clinical details of each of these cases with larger fragments are summarised in table 1. Among 27 sporadic FSHD cases, the size distribution ranged from 10 to $48 \mathrm{~kb}$ (mean 17.8, SD 8.83), while the size distribution among 103 familial cases ranged from 10 to $>48$ (mean 22.0, SD 7.1) $(p=0.01)$. Three fragment bands were evident in three unrelated subjects with FSHD. Among the control population, the smallest fragment size detected was $38 \mathrm{~kb}( \pm 2 \mathrm{~kb})$, while the majority had fragment sizes that were within the limiting mobility of the DNA on the agarose gel $(>48 \mathrm{~kb})$. Nineteen subjects had smaller fragment sizes that ranged between 38 and $48 \mathrm{~kb}$ (fig 2). In each FSHD patient with a double digest $(E c o \mathrm{RI} / B \ln \mathrm{I})$ fragment of $<28 \mathrm{~kb}$, there was an approximately $3 \mathrm{~kb}$ reduction in the size of the double digest fragment compared to the EcoRI single digest fragment and without the appearance of other new fragments $<48 \mathrm{~kb}$.

\section{Discussion}

Among the 400 control chromosomes, the smallest fragment observed with the EcoRI/ $B \ln$ I double restriction enzyme digest was 38 $\mathrm{kb}( \pm 2 \mathrm{~kb})$, indicating that test specificity below this level is at or very near to $100 \%$ (lower $95 \%$ CI $98.2 \%$ ). This is in contrast to the $76 \%$ test specificity associated with the presence of frag- 


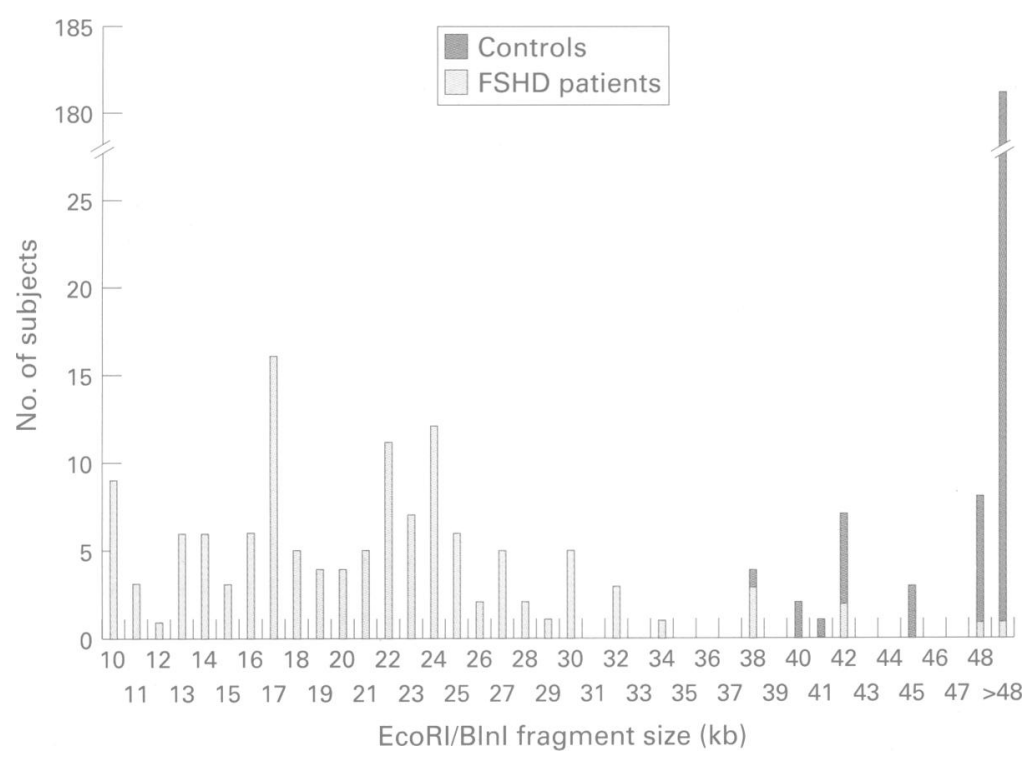

Figure 2 Size distribution of the smallest variable allele using EcoRI and BlnI restriction enzymes with D4F104S1 (p13E-11) in 200 controls and 130 unrelated FSHD patients.

ment sizes of $28 \mathrm{~kb}$ or less generated by a single EcoRI restriction digest. ${ }^{45}$ Accordingly, these data confirm that $B \ln I$ cleavage of the 3.3 kb D4Z4 repeats derived from the $10 \mathrm{q}$ locus ${ }^{11}$ greatly increases the test specificity associated with the detection of smaller $4 \mathrm{q}$ fragments. In addition, the data confirm the prediction of Deidda et $a l,{ }^{11}$ based on restriction site mapping, that among those affected with FSHD the size distribution of fragments created by $E c o R I / B \ln \mathrm{I}$ double restriction enzyme digest is approximately $3-5 \mathrm{~kb}$ smaller than the previously observed size distribution associated with single $E c o$ RI restriction digest. Thus, there has been a useful additional separation of disease associated smaller fragments from the larger fragments found in normal controls, and at the $34 \mathrm{~kb}$ level, the test sensitivity is $94.6 \%$ (95\% CI $89.2-97.8 \%)$, while specificity appears to be $100 \%$. In addition, the test sensitivity and specificity estimates derived from these data remain unaltered in the range between 34 and $38 \mathrm{~kb}$, indicating that the likely standard error associated with estimation of fragment sizes in this range will not have a significant impact on test accuracy, particularly when used with closely positioned standard high molecular weight DNA markers. While the $10 \mathrm{q}$ fragment has been successfully eliminated by the use of $B \ln I$ in this study, we would, however, still urge caution in this interpretation for diagnostic molecular testing, as a few exceptional alternatively defined apparent controls with EcoRI/ $B \ln \mathrm{I}$ fragments between $30-38 \mathrm{~kb}$ have been noted in other unpublished series from other centres (Naarden, personal communication, 1996). Of interest, in three unrelated FSHD patients, three alleles were observed following complete $E c o \mathrm{RI} / B \ln \mathrm{I}$ digestion. The occurrence of these additional bands among the FSHD affected group possibly suggests the presence of a previously unsuspected cross hybridising sequence or duplication of the 4 q35 sequence, the significance of which remains unknown. While there was no evi- dence of a third band among the control cases, such bands would only be apparent if their sizes were sufficiently small to be below the rate limiting mobility of the gel, or the possibility remains that the additional bands are only specific to FSHD. While this evidence, suggestive of the occurrence of a duplication, or of another cross hybridising sequence, does not influence the sensitivity and specificity of the test, it is being further investigated with pulsed field gel electrophoresis to determine the size and distribution of the larger fragments among those with three alleles.

The presence of a deletion of an integral number of D4Z4 repeats which do not appear to contain any expressed sequences ${ }^{9}$ and are in close proximity to $4 \mathrm{q}$ telomeric sequences has led to the suggestion that the mechanism underlying the disease could be position effect variegation (PEV) ${ }^{15}$ Experiments in Drosophila and yeast have shown that physical proximity to telomeric heterochromatin may actively suppress gene expression. ${ }^{16}$ The occurrence of normal range fragment sizes in seven FSHD cases confirms that there is more than one mechanism responsible for FSHD. Disease phenocopies may occur with the presence of an indistinguishable muscular dystrophy possibly overlapping with another clinical phenotype. Diseases which may produce a very similar phenotype, although usually distinguishable by EMG and biopsy features, include spinal muscular atrophy and the scapuloperoneal neuropathies. ${ }^{17}{ }^{18}$ Some cases, however, are not distinguishable even when the strictest of diagnostic criteria used in linkage studies are applied. Indeed, most linkage studies suggest that up to $5 \%$ of families are not linked to the $4 \mathrm{q} 35$ locus. ${ }^{6}$ It is possible that some of these people may either have a mutation elsewhere in the genome (genetic heterogeneity) or have point mutations or other rearrangements in a separate $4 \mathrm{q} 35$ gene, located proximal to $\mathrm{D} 4 \mathrm{Z} 4$.

This study has identified a potential subgroup of FSHD patients in whom there is no apparent correlation between smaller EcoRI/ $B \ln \mathrm{I}$ fragments and the expression of the disease. Reassessment of the seven unrelated FSHD patients with fragment sizes of $38 \mathrm{~kb}$ or more showed a range of unusual aspects, although all had typical features of FSHD that fell within the diagnostic criteria for FSHD. In one sporadic case with a fragment of $38 \mathrm{~kb}$, onset was in early infancy and another subject had a de novo fragment of $48 \mathrm{~kb}$ compared to clearly distinguishable fragments $>48 \mathrm{~kb}$ in the parents. In another family the mother was reported to have had typical but mild FSHD, one of two daughters with FSHD died at 17 years of age from cardiac failure, and in the other the FSHD was associated with treated hypothyroidism. Among the four familial cases, linkage data from at least one family suggest that it may not be linked to the $4 \mathrm{q} 35$ locus. Interestingly, the $38 \mathrm{~kb}$ fragment observed in this family is at the extreme low end of the range seen in the control population. In addition, six of the seven cases have fragment sizes that fall within the lowest $10 \%$ of the size range seen in the control population. Consan- 
guinity was present in a family of four sibs each of whom had typical features of FSHD, in contrast to their father who was reported to be only mildly affected. While linkage data in this family were consistent with linkage to the $4 \mathrm{q} 35$ locus, the fragment size in this family was too large to be resolved ( $>48 \mathrm{~kb})$. Explanation to account for these rare exceptions to the rule of deletion of $\mathrm{D} 4 \mathrm{Z} 4$ repeats at $4 \mathrm{q} 35$ as the cause of FSHD must await eventual molecular definition of an expressed FSHD gene.

The difference between the mean small fragment size observed in sporadic and familial cases supports previous findings, ${ }^{19}{ }^{20}$ and also may prove useful for the diagnostic evaluation of apparently sporadic cases as they are more likely to have unambiguously small $E c o \mathrm{RI} / B \ln \mathrm{I}$ fragments.

In conclusion, these data clearly show that the Southern blot analysis with DNA probe p13E-11 using enzymes EcoRI and BlnI has greatly improved the molecular diagnostic test for FSHD. In FSHD patients with fragment sizes smaller than $35 \mathrm{~kb}$, this test has a sensitivity approaching $95 \%$ while specificity approaches $100 \%$. This represents a major step forward for both diagnostic confirmation as well as genetic counselling for those at risk of inheriting FSHD.

We are grateful to all referring clinicians for patient samples, in particular Drs A Fryer, A Colley, S Bundy, W Reardon, A Norman, T Cole, G Woods, A Hammans, J Harvey, N Haites, C Bennett, and A Green. We thank Dr R Newcombe for statistical assistance and the Wellcome Trust and AFM for their financia support.

1 Padberg GW, Lunt PW, Koch M, Fardeau M. Diagnostic criteria for facioscapulohumeral muscular dystrophy. Neuromusc Disord 1991;1:231-4

2 Lunt PW, Harper PS. Genetic counselling in facioscapulohumeral muscular dystrophy. $\mathcal{F}$ Med Genet 1991;28:655-64.

3 Wijmenga C, Frants RR, Brouwer OF, Moerer P, Weber JL, Padberg GW. Location of facioscapulohumeral muscular dystrophy gene on chromosome 4. Lancet 1990;336:651-3.
4 Wijmenga C, Hewitt JE, Sandkujil LA, et al. Chromosome 4q DNA rearrangements associated with facioscapulohumeral muscular dystrophy. Nat Genet 1992;2:26-30.

5 Upadhyaya M, Jardine P, Maynard J, et al. Molecular analysis of British facioscapulohumeral dystrophy families for $4 \mathrm{q}$ DNA rearrangements. Hum Mol Genet 1993;2:981-7.

6 Gilbert JR, Stajich JM, Wall S, et al. Evidence for heterogeneity in facioscapulohumeral muscular dystrophy (FSHD) Am F Hum Genet 1993;53:401-8.

7 Bakker E, van der Wielen MJR, Voorhoeve E, et al. Diagnostic, predictive, and prenatal testing for facioscapulohumeral muscular dystrophy: diagnostic approach for sporadic and familial cases. F Med Genet 1996;33:29-35.

8 Weiffenbach B, Bagley R, Falls K, et al. Linkage analysis of 5 chromosome 4 markers localises the facioscapulohumeral muscular dystrophy gene to distal $4 \mathrm{q} 35 . A m f$ Hum Genet 1992;51:416-23.

9 Hewitt JE, Lyle R, Clark LN, et al. Analysis of the tandem repeat locus $\mathrm{D} 4 \mathrm{Z} 4$ associated with facioscapulohumera muscular dystrophy. Hum Mol Genet 1994;3:1287-95.

10 Wijmenga C, van Deutekom JCT, Hewitt JE, et al. Pulsed-field gel electrophoresis of the D4F104S1 locus reveals the size and the parental origin of the facioscapulohumeral muscular dystrophy (FSHD) associated deletions. Genomics 1994;19:21-6.

11 Deidda G, Cacurri S, Piazzo N, Felicetti L. Direct detection of $4 \mathrm{q} 35$ rearrangements implicated in facioscapulohumeral muscular dystrophy (FSHD). $\mathcal{f}$ Med Genet 1996;33:361-5.

12 Jardine PE, Upadhyaya M, Maynard J, Harper PS, Lunt PW. A scapular onset muscular dystrophy without facia involvement - possible allelism with facioscapulohumeral muscular dystrophy. Neuromusc Disord 1994;4:477-88.

13 Feinberg AP, Vogelstein BA. A technique for radiolabeling DNA restriction fragments to a high specific activity. Anal Biochem 1984;137:266-7.

14 Clopper J, Pearson ES. The use of confidence or fiducial limits illustrated in the case binomial. Biometrika 1934;26 404-13.

15 Henikoff S. Position effect variegation after 60 years. Trends Genet 1990;6:422-6.

16 Wilson C. Position effects on eukaryotic gene expression. Annu Rev Cell Biol 1990;6:679-714

17 Furukawa T. Neurogenic FSH muscular-atrophy. Muscle Nerve 1995;2:S85-95.

18 Tawil R, Myers GJ, Weiffenbach B, Griggs RC. Scapuloperoneal syndromes - absence of linkage to the 4q35 locus. Arch Neurol 1995;52:1069-72.

19 Lunt PW, Jardine P, Koch MC, et al. Correlation between fragment size at D4F104S1 and age at onset or at wheelchair use, with a possible generational effect, accounts for much phenotypic variation in $4 \mathrm{q} 35$ facioscapulohumeral muscular dystrophy (FSHD). Hum Mol Genet 1995;4:951-8.

20 Lunt PW, Jardine PE, Koch MC, et al. Correlation between fragment size at D4F104S1 and age at onset or at wheelchair use, with a possible generational effect, accounts for much phenotypic variation in $4 \mathrm{q} 35$ facioscapulohumeral muscular dystrophy (FSHD). Hum Mol Genet 1995;4:1243-4. (Erratum to Hum Mol Genet 1995;4 951-8.) 